REVISTA X, Curitiba, volume 12, n.2,p.105-129,2017

\title{
PERCEPÇÕES DE ESTUDANTES DE TRADUÇÃO ESPANHOL-PORTUGUÊS ACERCA DO PROCESSO DE BILETRAMENTO
}

\author{
Perceptions of Spanish-Portuguese Translation Student's on the Biliteracy Process
}

\author{
Ana Laura dos Santos MARQUES, USACH ${ }^{1}$
}

\begin{abstract}
RESUMO: Este trabalho enfoca a percepção do biletramento presente no contexto universitário chileno em que o desenvolvimento da escrita tem propósitos específicos para os estudantes de tradução espanhol-português: transitar entre línguas para transmitir significados. O conceito de biletramento (Hornberger, 2003; 2013) refere-se às instâncias em que a comunicação ocorre em duas ou mais línguas dentro e em torno da escrita. É precisamente a percepção da correlação entre a habilidade de escrita em duas línguas o problema discutido neste artigo. Para essa proposta, ressalto a proximidade entre as línguas espanhola (LM) e portuguesa (LE), propiciadora da compreensibilidade mútua que indefine as fronteiras entre as duas línguas. Os objetivos deste trabalho são descrever e analisar as opiniões dos estudantes de tradução acerca do incremento de sua habilidade de escrita e verificar se eles a compreendem como um processo contínuo: desde a língua materna à língua estrangeira e vice-versa. Para isso, utilizo uma metodologia qualitativa, com dados analisados a partir de entrevistas semiestruturadas. Os resultados dessa pesquisa buscam responder se, nas percepções dos estudantes, está plasmada a ideia de complementariedade através das práticas de produção de textos no contexto de formação acadêmica, sobretudo nas possíveis correlações entre a língua estrangeira e a língua materna.
\end{abstract}

PALAVRAS-CHAVE: Biletramento; Escrita acadêmica; Aprendizagem de línguas próximas: português-espanhol

ABSTRACT: This work deals with the perception of the biliteracy process occurring in a Chilean university setting, in which the development of writing skills has specific purposes for the Spanish-Portuguese translation students, i.e. moving through languages to convey meanings. The concept of biliteracy (Hornberger, 2003; 2013) refers to situations in which communication occurs in two or more languages in or around writing. More precisely, this article debates the perception of the correlation between the writing skills in two languages. In this proposal, I underline the similarity between Spanish (MT) and Portuguese (FL), which enhances their mutual comprehension and blurs their frontiers. This work intends to describe and analyze the opinions of translation students on the improving of their writing level, as well as to verify whether they understand this increase as a continuous process: from the mother tongue to the foreign language and vice versa. Therefore, a qualitative methodology was chosen to analyze data obtained from semi-structured interviews. The results aim at revealing if students perceive textual

\footnotetext{
${ }^{1}$ Docente de Língua Portuguesa no curso de Lingüística Aplicada a la Traducción, Departamento de Lingüística y Literatura - Universidad de Santiago de Chile. Doutoranda, bolsista Conicyt, do Programa de Doutorado en Lingüística da Pontifícia Universidad Católica de Chile. ana.marques@usach.cl
} 
production practices as complementary in their academic training, especially regarding possible correlations between foreign language and mother tongue.

KEY WORDS: Biliteracy; Academic Writing; Close languages learning: PortugueseSpanish

\section{INTRODUÇÃO}

Poder usar a língua por meio de um conjunto de sinais gráficos para transmitir mensagens se entende atualmente como "natural" quando observamos as práticas de interação nas quais escrever passa a ser "essencial para a sobrevivência no mundo moderno" (MARCUSCHI, 2010, p.16). Mais que estatus a quem teve acesso à alfabetização e é capaz de entender a sua função mediadora, o uso da escrita permite também a inserção dos indivíduos em uma sociedade marcadamente dependente dos símbolos que constituem os meios de interação, promovendo contatos cada vez mais atemporais entre os usuários. Essa inserção na sociedade através dos usos da escrita dá origem ao termo e às pesquisas em torno do letramento.

Letramento envolve "as mais diversas práticas em torno da escrita em sociedade, em suas mais variadas formas, segundo os diferentes graus de apropriação que o indivíduo pode chegar a ter das habilidades de ler e produzir textos" (MARCUSCHI, 2010, p.25). Quando a produção e a leitura de textos se ampliam também ao conhecimento (e uso) de outra língua que é incorporada com suas próprias formas de interação social, conformamse contextos de biletramento.

Neste trabalho, reviso as percepções dos aprendizes acerca do desenvolvimento da escrita em duas línguas no âmbito das práticas acadêmicas para a formação de tradutores. Esses estudantes de tradução encontram-se, por um lado, conectados e dependentes do que podem e vão ser capazes de fazer com sua língua materna (LM) e, por outro lado, condicionados a um desenvolvimento comunicativo nas línguas estrangeiras com as quais vão trabalhar. Como resultado, terão em seu repertório dois sistemas para interagir nos âmbitos social e profissional. Esse espaço de formação e usos das línguas de trabalho em práticas específicas de leitura e escrita vão conformar um contexto de biletramento, termo entendido como a capacidade de alternar o uso de duas línguas nas interações que se dão dentro e em torno da escrita (HORNBERGER, 2003; 2013). Esse conceito é derivado dos estudos sobre bilinguismo, da emergência de contatos 
multilíngues que sempre se deram em nossas sociedades, mas que a partir da intensificação dos processos de migração e do acesso à internet e suas novas formas de comunicação, saltaram à vista como um processo real e irreversível no mundo. Além disso, está a necessidade de produzir textos para a inserção em práticas discursivas situadas. O usuário de duas ou mais línguas transita pelos sistemas que conhece e é capaz de produzir diferentes registros de língua escrita, segundo as necessidades da situação e os benefícios que este uso lhe trará como conhecedor desse processo de comunicação. Neste artigo, centro-me em descrever e em interpretar as percepções dos estudantes universitários sobre o biletremanto no qual estão envolvidos em sua formação acadêmica.

Quais situações e requerimentos estão envolvidos no desenvolvimento da escrita acadêmica em LM e em LE? Essas práticas de escrita seriam próximas nos dois sistemas? A resposta mais evidente deveria estar na produção de sentido, no potencial epistêmico do ato de escrever (CARLINO, 2004), num marco de "formação científica e disciplinar". As transferências de aspectos da habilidade de escrita já consolidados em LM vão estar presentes no processo de desenvolvimento dessa mesma habilidade em LE (COLOMBI, 2006; SCHLEPPEGRELL, 2006; JIANG, 2011; RYSHINA-PANKOVA, 2015). Porém, há poucas pesquisas que indagam o que acontece no sentido contrário, isto é, em que contribuiria o aprendizado da escrita em LE à LM para esses estudantes. Considerando tratar-se de uma habilidade que não pode ser caracterizada como totalmente concluída em determinada fase de aprendizagem dos indivíduos, a percepção da correlação entre a escrita na LE e na LM é precisamente o problema discutido no presente trabalho.

É um fator importante para as análises que se estabelecem com relação ao ensino e aprendizagem de línguas a comparação entre LM e LE, especificamente com o levantamento das características dos dois sistemas em relação à distância entre as formas já conhecidas e por saber com as quais o aprendiz terá que lidar. Para a aprendizagem do português como língua estrangeira por hispano-falantes, o fenômeno da "compreensibilidade mútua" (termo estabelecido na área por Almeida Filho, 1995) converte-se em uma variável importante neste estudo. Consideradas línguas próximas, com um desenvolvimento que marca as semelhanças nos planos morfossintáticos e fonético-fonológico, devem receber no processo de ensino e aprendizagem um enfoque especial, sem perder de vista as vantagens e desvantagens de fomentar a produção linguística do aprendiz já nos primeiros contatos com a língua (o português para hispanofalantes ou o espanhol para luso-falantes). De uma facilidade inicial que lhes permite 
avançar muito rápido em termos comunicativos, passa-se a um longo período de acomodação na aprendizagem. Isso se deve, em princípio, ao fato de que se há compreensão, a preocupação com a forma deixa de ser essencial. Assim, revela-se a complexidade nesse contato tão próximo entre os dois sistemas no plano da produção, sendo que as marcas das transferências da LM, tanto na oralidade quanto na escrita, representarão as dificuldades dos aprendizes em delimitar as fronteiras de um e de outro sistema.

Ao enfocar o biletramento, ressalto que, na formação de tradutores espanholportuguês, o desenvolvimento da habilidade de escrita corresponde a uma formação interdependente dos avanços nas duas línguas, que permite aos estudantes aproximaremse dos registros especializados, promover conhecimento e gerar textos de acordo com a produção científica e disciplinar própria de seu campo acadêmico. Para o caso da convivência das línguas mencionadas, parece haver uma correlação entre as experiências de escrita nas duas línguas, à medida em que a habilidade vai se consolidando. Isso significa que os conhecimentos sobre os registros escritos da língua estrangeira poderiam modificar/interagir com os conhecimentos da LM. Essa correlação se refletiria nos casos em que os aprendizes estão capacitados e conseguem alcançar um bom domínio da habilidade para mover-se entre um ou outro sistema de escrita segundo o contexto de exigência. Os objetivos com esse estudo são descrever e analisar suas percepções sobre a escrita em torno das línguas de sua formação profisssional com o fim de responder à pergunta: haveria algum tipo de consideração, por parte dos estudantes, de que a habilidade de escrita é um processo contínuo e circular de desenvolvimento desde a LM à LE e desde a LE à LM?

Proponho uma pesquisa qualitativa caracterizada, segundo Vasilachis de Gialdino (2012, p.28-29), pelo interesse em compreender a perspectiva dos sujeitos em seus processos de interação com a realidade social, por ser eminentemente descritiva, interpretativa, indutiva e reflexiva e pela intenção de buscar empiricamente respostas. Nesta primeira tentativa de compreensão da percepção dos estudantes acerca do biletramento, não considero a observação de transferências e/ou interferências linguísticas nas produções escritas. Para a tarefa que proponho, a análise será baseada em dados obtidos nas respostas dos estudantes em entrevistas semiestruturadas, de modo a identificar seus pontos de vista sobre as suas práticas de escrita e os significados que lhes atribuem. Nesse sentido, este trabalho busca compreender os valores e os entendimentos 
dos sujeitos e conforma um estudo de caso.

Os temas que discuto nas seguintes seções têm como objetivo estabelecer pontos de contato entre saber escrever na LM e suas implicações na LE. Ademais, apresento como o conceito de biletramento é definido para sua aplicação ao contexto universitário em que realizo este trabalho.

\section{SABER ESCREVER EM LM E EM LE}

A escrita é "mediadora na ativação das competências comunicativas de um aprendiz de línguas em seus espaços de convivência social para atividades de recepção, produção, interação e mediação linguística" (QuaREP², 2011, p.15). De fato, são vários os estudos que abordam a convergência dos domínios de escrita já consolidados na LM para a abordagem da escrita em LE/L2 (CUMMINS, 1979); a escrita para o desenvolvimento de conhecimentos linguísticos, por exemplo, quanto ao domínio de vocabulário e/ou de sintaxe a partir de práticas de produção de textos em LE (CORONADO, 2016); o domínio de gêneros textuais específicos (JÚDICE, 2013) e o domínio de fatores de textualidade - coesão, coerência, intertextualidade, intencionalidade, informaticidade, internacionalidade e situacionalidade em processos de retextualização (DELL'ISOLA, 2012).

A escrita "demanda competências linguísticas anteriores" (GOMES \& PINHEIRO-MARIZ, 2011, p.116), como são a leitura e a expressão oral, pois todas essas habilidades socioculturais estão envolvidas na sua produção. Inegavelmente, entre a compreensão e a produção linguística há fatores variáveis de interferência, por exemplo, as motivações, atitudes e propósitos em relação aos usos da LE (GROSSO \& MOUTINHO, 2012).

$\mathrm{Na}$ interseção dos estudos sobre os processos de escrita em LM e em LE ou em segundas línguas (L2) em uma perspectiva socio-semiótica, Matthiessen (2009) afirma que são processos similares quando analisados em contextos educacionais, dado que correspondem a uma ampliação dos contextos de registros da(s) língua(s). O autor oferece dois pontos importantes para a discussão sobre a aprendizagem de LE/L2 de forma

\footnotetext{
${ }^{2}$ Quadro de referência para o ensino de português no estrangeiro. Documento eletrônico. Disponível em: http://www.instituto-camoes.pt/epe-inscricoes/quarepe
} 
específica: 1) a ideia de que se trata de uma complementariedade entre uma aprendizagem e outra (LM-LE/L2, já que a LM pode ser um recurso para o desenvolvimento da LE/L2 e 2) a ampliação do conhecimento acerca dos registros de uma e de outra forma. O segundo ponto permite estabelecer uma conexão com o termo interculturalidade: usar a L2 para significar em espaços de interação, ou seja, usar a língua em aprendizagem para falar de aspectos da cultura e da sociedade que são comuns ou diferentes, pertence às práticas discursivas em geral, independente de que se trate de LE/L2 ou LM:

\begin{abstract}
Cuando se aprende lenguas, se acumulan sus propios potenciales significado personalizados como parte del potencial significado colectivo que constituye la lengua, y se acumulan estos potenciales significados personales expandiendo gradualmente sus propios repertorios de registro, sus propias acciones, en el potencial significado colectivo. A medida que expanden sus propios repertorios de registro, pueden asumir funciones en una creciente gama de contextos, convirtiéndose semióticamente en más poder y versatilidad (MATTHIESSEN, 2009, p.123).
\end{abstract}

Esta expansão dos repertórios de registros e dos potenciais significados que os aprendizes vão desenvolvendo a partir de suas aprendizagens em contextos formais, segundo as afirmações de Matthiessen (2009), conformam a base para a discussão da escrita como atividade dependente do contexto e das experiências nas interações que surgem com sua função social. Para produzir textos em uma L2/LE há, em primeiro lugar, uma dependência dos conhecimentos e práticas já consolidados na LM, conforme a expansão de registros tenha se estabelecido e o indivíduo já os tenha compreendido em termos de mediação social. Isso sugere que há um entendimento da noção de letramento como o resultado do uso da leitura e da escrita para a promoção de sujeitos críticos e hábeis, conectados com os usos requeridos em diferentes instâncias de convivência social (SOARES, 2009).

Em LE, o desenvolvimento do letramento tem objetivos muito semelhantes aos da LM, ainda que o grau de especificidade possa variar quanto aos propósitos de aprendizagem (mais ou menos comunicativa), às experiências prévias com a leitura e com a escrita e aos graus de envolvimento com a língua em aprendizagem. Lousada e Ferreira (2016) criticam a forma como percebem o tratamento dado ao letramento no contexto universitário e apontam que a escrita em LE costuma desenvolver-se de modo descontextualizado, tanto das práticas da LM quanto das práticas da própria LE, afastada de sua função social para a comunicação e interação, o que explica, em parte, as dificuldades dos estudantes em compreender e produzir textos. Essa primeira 
consideração das formas de escrita como usos sociais em duas ou mais línguas abre caminho para a conceitualização do biletramento, termo discutido na seguinte seção.

\section{APROXIMAÇÕES AO CONCEITO DE BILETRAMENTO}

O biletramento (GENTIL, 2005; HORNBERGER, 2003; HORNBERGER, 2013) refere-se à comunicação em torno da escrita em mais de uma língua. Na prática das duas línguas de modo alternativo, estão considerados os graus de conhecimento envolvidos, a função que o aprendiz atribui a esses conhecimentos, o trânsito entre um e outro sistema e as interferências de uma língua sobre a outra, do mesmo modo que o conceito de bilinguismo costuma ser caracterizado. Sobretudo, há uma interdependência no uso de ambos os sistemas, pois LM e LE passam a conviver e complementar-se nas diferentes instâncias de comunicação que requer a escrita. Gentil (2011) aponta que no biletramento estão envolvidas as mesmas dimensões que o letramento implica: linguísticas, cognitivas e socioculturais da leitura e da escrita.

As conexões entre a aprendizagem da LM e da LE têm sido objeto de estudo de pesquisas relacionadas com o termo. Segundo Jiang (2011, p.178), esses trabalhos referem-se à existência de duas perspectivas de análise. A primeira, denominada "Hipótese de Interdependência Linguística", considera o letramento em LM como uma base experimental para o desenvolvimento da LE, pois os conhecimentos não se transferem à outra língua, mas sim se constituem como um ponto de partida para compreender os diversos aspectos requeridos pela escrita nela. A segunda perspectiva, "Hipótese do Umbral Linguístico", argumenta que os aprendizes terão que desenvolver certo nível de competência linguística em LM antes de poder melhorar a compreensão de leitura na LE. As duas hipóteses não questionam a existência de transferências entre uma e outra língua, mas, sim, tentam prever quando essas transferências vão acontecer.

Os estudos acerca do biletramento vêm tentando definir suas características, seus processos típicos e as interferências do contexto para a convivência entre dois sistemas de escrita. Hornberger (2003) propõe o modelo de biletramento contínuo, dado que é um sistema inter-relacionado, complexo, dinâmico e em permanente mudança; influenciado pelo conhecimento do conteúdo que abarca uma gama de estilos e de gêneros pertencentes ao âmbito da LM e da LE. Os aprendizes bilíngues acedem a esses diversos conteúdos através dos meios de comunicação e de instrução, mediante à oralidade e à escrita. Esse 
conteúdo, enriquecido a partir de suas experiências com a leitura e com a escrita, fomenta o desenvolvimento do biletramento.

Sobre os contextos de biletramento, Cho (2010) destaca em sua pesquisa que esses incluem não só aspectos físicos, materiais e configurações visíveis em que as pessoas se dedicam à comunicação nas línguas particulares dentro ou em torno da escrita, mas também as perspectivas ou orientações pessoais, subjetivas e intersubjetivas a partir das quais cada um avalia e responde à interação. Para chegar a essa caracterização do contexto, o autor observou que as experiências e os valores dos indivíduos que transitam por contextos de biletramento não só provêm das condições sociais como também se baseiam nos valores e significados que atribuem à sua capacidade de escrever na primeira língua ou na língua materna. À medida que se orientam dentro desses contextos para envolver-se com a escrita nas línguas conhecidas, os indivíduos negociam suas identidades pessoais e sociais como sujeitos morais e como membros das comunidades linguísticas, culturais e acadêmicas.

Van der Walt (2013), por sua vez, amplia o conceito de biletramento para a noção de biletramento ativo em contextos educacionais: quando estudantes ativam e utilizam conscientemente mais de um idioma, dependendo das condições de produção/compreensão de um texto. Essa ativação dos idiomas que conhecem depende de que os professores abram espaços para que os alunos multilíngues usem os recursos que têm de forma consciente para a realização das diferentes tarefas.

Entre os estudos de biletramento, também se encontram os que têm tentado estabelecer uma relação entre biletramento e translinguismo, como o fazem Kwon y Schallert (2016). Esses autores propõem a associação entre os dois termos, válidos para caracterizar usos integrados e mistos de língua quando os indivíduos são beneficiados por ter incorporado as formas linguísticas (itens lexicais e aspectos gramaticais). Além disso, apresentam interações dinâmicas e funcionalmente integradas de dois idiomas que lhes permitem "hacer sentido, comunicar, dar forma a las experiencias y ganar la comprensión y el conocimiento del mundo" (Kwon \& Schallert: 2016, p.139). Transitar por dois ou mais sistemas linguísticos é, para esses autores, uma habilidade altamente desenvolvida que envolve estratégias criativas de usuários das línguas. Esse processo pode ser benéfico para os indivíduos, pois se poderia reconhecer neles sua capacidade para a compreensão profunda de significados e o reconhecimento de sutilezas nos textos. Kwon y Schallert 
(2016) admitem o translinguismo como uma ferramenta autorreguladora e fonte das estratégias fundamentais para as práticas de biletramento - escrita e leitura.

Essas perspectivas teóricas sobre biletramento representam como os trabalhos que relacionam o uso de duas ou mais línguas conseguem conectar as interferências da LM na LE como um contínuo, ainda que não se explicite em que medida a LE é também um recurso para o desenvolvimento contínuo da habilidade em LM. O ponto em comum desses estudos é que se desenvolveram em contextos acadêmicos em que o peso das instituições para os usuários das línguas envolvia suas interações com outros pares, a possibilidade de que os participantes refletissem sobre o seu pertencimento a esse espaço e a (re)produção do conhecimento disciplinar. Ainda que os participantes dessas pesquisas pertencessem à segunda geração de imigrantes e não estivessem em jogo as variáveis relacionadas com seus primeiros contatos com a LE, esse não é um tema menor na consideração de outros estudos sobre biletramento (ver, por exemplo, REYES, 2012).

\section{BILETRAMENTO NA FORMAÇÃO DE TRADUTORES}

Quando pensamos no contexto universitário em que a aprendizagem de uma LE é também o objetivo da formação acadêmica e profissional, é inevitável não considerar que as experiências de aprendizagem da escrita vão potencializar-se a partir de uma convergência de saberes individuais e especializados. As expectativas são de que as práticas de escrita nesse nível sejam geradoras de uma transformação de conhecimentos: desde a escrita em si mesma e os seus usos acadêmicos a um uso consciente e representativo do domínio dos registros especializados que fazem parte das diversas disciplinas, as quais conservam suas próprias marcas, estilos e modos de comunicar.

Carlino (2004:1) propõe discutir a escrita em termos de seus objetivos principais nos contextos universitários: promover os modelos de escrita vinculados com as disciplinas e ativar seu potencial epistêmico, pois é vista como "un instrumento para acrescentar, revisar y transformar el propio saber". Apesar disso, segundo a autora, é frequente que nas universidades se perca de vista o potencial cognitivo dessa habilidade no afã de transmitir conhecimentos especializados, supondo que esses saberes por si mesmos vão moldar o letramento dos estudantes. Isso favorece a reprodução de queixas dos professores universitários acerca da pouca capacidade de seus alunos de ler e produzir textos adequadamente em suas especialidades. Para Carlino (2004), nessas queixas, 
revela-se que os professores não se consideram responsáveis por contribuir com o desenvolvimento dessa habilidade, mas eles se esquecem de que:

existen prácticas discursivas propias de las disciplinas y profesiones, que son llevadas a cabo solo por las comunidades disciplinares y profesionales respectivas (...) Y no son accesibles para neófitos, a menos que algún experto los abra la puerta y comparta con ellos su cultura escrita. Incluso aunque se pensara que los docentes deben ocuparse solo de comunicar el conocimiento elaborado en cierta área (y no las modalidades de lectura y escritura en ella empleadas) sería todavía pertinente incluir la escritura en sus materias como herramientas para elaborar y apropiarse de ese saber conceptual (CARLINO, 2004, p.2).

Sem o conhecimento das formas de como se escreve nos textos de especialidade, a escrita acadêmica não terá êxito. Carlino (2004) defende a inclusão da prática de produção escrita através do curriculum universitário, ensinar a escrever e a pensar de forma integrada nos conteúdos de cada disciplina, de modo que o estudante possa elaborar e apropriar-se desse saber conceitual.

Há contextos de práticas de leitura e escrita que são, em si mesmos, a essência da formação acadêmica dos estudantes, ou seja, os saberes disciplinares se conformam e, ao mesmo tempo, dependem do letramento. É o caso da formação acadêmica de tradutores que engloba conhecimento e uso das línguas como um recurso de aprendizagem, de práticas acadêmicas que derivarão em práticas profissionais. O mais específico desse contexto é, sem dúvida, a formação disciplinar que se dá em torno das práticas de leitura e de escrita e envolve o conhecimento de mais de uma língua.

O curso de Lingüística Aplicada a la Traducción (LAT) na Universidad de Santiago de Chile (USACH) é o único no país a incorporar as línguas portuguesa e japonesa no contexto de formação universitária para fins profissionais. As habilitações oferecidas aos estudantes são português-inglês-espanhol e japonês-inglês-espanhol. Cabe mencionar que o ingresso à universidade corresponderá, para quase a totalidade dos alunos, ao primeiro contato que terão com as línguas portuguesa e japonesa, pois suas experiências prévias com línguas estrangeiras se resumem às aulas de inglês no ensino básico e médio. As disciplinas estão organizadas em torno a competências e contribuem para a formação esperada - uma declaração contida no documento denominado "Perfil de egreso" dos alunos. Os objetivos de todas as disciplinas deveriam centrar-se no desenvolvimento da expressão nas línguas de trabalho, tal como se apresenta na competência número 1: "Expresarse con fluidez en forma oral y escrita en las lenguas 
que utiliza profesionalmente". Nesse sentido, considera-se a importância das habilidades produtivas - oralidade e escrita como ferramentas fundamentais no desenvolvimento das diversas capacidades dos estudantes como propósito específico da sua formação como tradutores. A LM, o espanhol, está presente nesse processo e também nos processos de letramento em LE e poderia também beneficiar-se dos avanços e questionamentos que a aprendizagem de outras línguas de trabalho lhes propiciam.

\section{PORTUGUÊS E ESPANHOL: PROXIMIDADE E INFLUÊNCIAS MÚTUAS}

A proximidade entre as duas línguas está referida em muitos estudos da área da linguística que ressaltam as necessidades específicas referentes ao seu processo de aprendizagem. Grande parte dos trabalhos publicados no Brasil no fim da década de 1990 e início da década de 2000 (FERNÁNDEZ-RODRÍGUEZ, 1998; FERREIRA, 1998; GRANNIER, 2002; JÚDICE, 2002) problematizaram a questão da "compreensibilidade mútua" e do contato com a cultura expressa pela língua meta (português ou espanhol). Trata-se de um par linguístico não só com uma origem em comum, mas também com grande parte de seu léxico, de sua sintaxe e até parte de seus sistemas fonético-fonológico compartilhados.

Nos anos 1990, os estudos de Almeida Filho (1995), Santos (1998) e Ferreira (1998) chamaram a atenção no âmbito acadêmico para a facilidade que a aprendizagem das duas línguas poderia representar. Esses trabalhos faziam referência a uma forma mista de língua que se produzia, uma língua intermediária, o portunhol. Alguns anos mais tarde, Alonso Rey (2005) especificou essa noção, tentando derrubar o mito da "facilidade enganosa" para a aprendizagem das duas línguas. Derivado precisamente da compreensibilidade mútua das línguas, o caráter de falso iniciante para os aprendizes é um fato de grande preocupação nessas pesquisas, já que este é capaz de reconhecer sons, palavras e organizações sintáticas como coincidentes com a sua LM. Assim, já nos primeiros contatos com a língua em aprendizagem, tende a não se ver impedido de produzi-la. Algumas fronteiras são apagadas e é gerado um sistema intermediário, muito útil para a comunicação imediata - baseado no princípio da compreensibilidade. Porém, trata-se de um "conhecimento movediço" (ALMEIDA FILHO, 1995), já que há uma falta de clareza na percepção das diferenças entre as duas línguas. 
É um fato que o grau de compreensibilidade mútua entre as duas línguas gera vantagens e desvantagens no processo de aprendizagem, tendo inclusive impacto nas atitudes dos aprendizes com relação à língua meta. Silva (2013) refere-se à resistência dos aprendizes de línguas tão próximas, como português e espanhol, em assumirem seu nível inicial de aprendizagem, já que há uma relativa facilidade de compreensão do texto oral e escrito.

Para os estudantes hispano-falantes de tradução, a atitude com relação ao seu objeto de estudo, a língua portuguesa - muda nos primeiros contatos com o idioma. De uma facilidade inicial que lhes permite avançar muito rápido em termos comunicativos, passa-se a um longo período de acomodação na aprendizagem. Ao parecer, por existir algum grau de compreensão - em geral, alto -, há um menor cuidado com a forma da produção. Não é raro observar as dificuldades desse processo quando percebem que as habilidades linguísticas desenvolvidas até determinado momento não lhes permitem garantir um bom nível de qualidade nas suas atividades de tradução.

A habilidade de escrita para os aprendizes de português corresponde a um nível alto de coincidências entre as duas línguas: desde a morfossintaxe à estruturação de parágrafos, desde os fatores de textualidade até a produção de gêneros textuais (ROTTAVA, 2010). Porém, é fato que o aprendiz irá se encontrar "com dificuldades relativas à mobilização dos recursos textuais e sintáticos" do português (JÚDICE, 2013:151).

$\mathrm{Na}$ análise a seguir, considero as percepções dos estudantes de tradução do par espanhol-português, tendo em vista os fatores: a) as influências mútuas entre a LE e a LM, não somente pela proximidade que apresentam, mas também pela complementariedade das práticas de escrita que o contexto de formação proporciona, e b) a aplicação do conceito de biletramento a esse contexto de formação: como o percebem e como caracterizam suas práticas nas duas línguas.

\section{DESENVOLVIMENTO DA PESQUISA}

Este trabalho consiste em uma pesquisa qualitativa na medida em que toma como princípio a busca de interpretações de um problema que requer descrição e compreensão de experiências em torno da escrita em um ambiente de aprendizagem específico, com 
dados eminentemente verbais (as respostas induzidas pela pesquisadora aos alunosparticipantes), de modo a interpretar o que pensam sobre suas práticas, quais significados lhes atribuem. Os dados para análises são obtidos a partir do método de entrevistas semiestruturadas. Justifico a escolha desse método por considerá-lo a melhor forma para aproximar-me dos estudantes, identificar e compreender como eles "percebem e significam sua realidade" (DUARTE, 2004:215). Pretendo gerar uma instância de reflexão para os estudantes envolvidos por meio de uma pauta de perguntas baseadas nos objetivos traçados para este trabalho. As reflexões motivadas pelas entrevistas deveriam converter-se em dados que permitissem responder à pergunta de pesquisa deste estudo.

\section{Contexto de pesquisa}

As entrevistas semiestruturadas foram realizadas com quatro estudantes do curso de Lingüística Aplicada a la Traducción, habilitação espanhol-inglês-português que aceitaram participar como informantes para este trabalho. Conformou-se este grupo considerando que representariam uma pequena amostra da turma em que estavam. Cada um desses quatro alunos apresentava desde um bom nível de domínio da escrita, constatado a partir da apreciação das avaliações feitas dos seus textos por professores de diversas disciplinas, a um nível relativo de dificuldade com a escrita, observando-se suas produções escritas e o resultado de suas avaliações. Esse critério de seleção permite obter relatos variados em termos de experiências com a escrita no âmbito universitário. Com as entrevistas se buscava promover uma reflexão pessoal acerca dessa habilidade, por isso se considerou relevante o fato de que o grupo de estudantes não fosse homogêneo quanto ao seu desempenho nas diversas tarefas acadêmicas que realizavam.

Os quatro participantes deste trabalho estavam matriculados nas disciplinas obrigatórias Produção de textos em Língua Portuguesa II e Produção de textos em Língua Inglesa II no $2^{\circ}$ semestre de 2016. Além disso, haviam cursado as disciplinas Expressão oral e escrita em espanhol I, II, III e IV em semestres anteriores.

\section{Pauta para as entrevistas}

Para o desenvolvimento das entrevistas, foi usada, de modo flexível, a pauta a seguir com o fim de orientar a conversa. Outras perguntas poderiam ser acrescentadas de 
acordo com cada interação, para motivar os estudantes a relatarem suas experiências e precisar suas respostas.

\section{Quadro 1: Pauta para as entrevistas}

1. Você considera que escreve muito nas disciplinas do curso de LAT? Em geral, que tipos textos você escreve? Como você os avaliaria: estão bons, são aceitáveis, são complexos, são difíceis de ler ou de produzir?

2. Quando você tem que produzir um texto em sua LM, segue algum modelo ou roteiro?

3. Qual foi o último texto que você escreveu em espanhol? Que aspecto você considera ter sido o mais fácil nessa tarefa? Na sua opinião foi um bom texto?

4. Como você analisa o desenvolvimento da sua escrita desde a sua entrada na universidade até o presente momento?

5. Em português: quando você tem que produzir um texto, segue algum modelo ou roteiro? Para a sua última produção de textos, reflita sobre como você estruturou o seu trabalho, como o revisou, quais recursos você utilizou...

6. Compare os dois processos de escrita: na sua LM e em português.

a) Quando escrevo em minha LM nas disciplinas do curso, eu me preocupo/ me oriento / me considero... (mencionar alguma opinião concreta sobre essa atividade) b) Quando escrevo em Português nas disciplinas do curso, eu me preocupo/ me oriento / me considero... (mencionar alguma opinião concreta sobre essa atividade)

7. Você percebe a presença das línguas estrangeiras que você conhece (ao momento de usar alguma palavra, ao esquecer como se escreve) quando você tem que escrever em espanhol?

8. Você acha que aprender a escrever em outras línguas melhora a sua escrita em LM? Em que aspecto específico?

As entrevistas foram conduzidas em espanhol para que os alunos pudessem livremente falar de suas experiências com a escrita.

\section{ANÁLISES DOS DADOS}

Os dados obtidos a partir das entrevistas permitem uma categorização temática que conforma um panorama das percepções dos estudantes sobre seu biletramento.

\section{Percepção 1: A escrita é uma prática constante na formação em tradução}

Os quatro estudantes se referem ao fato de que escrevem "muito" nas diferentes disciplinas do curso de LAT, principalmente no nível em que se encontram. Destacam que as disciplinas de produção de textos em línguas estrangeiras (português e inglês) e as de introdução à tradução exigem a escrita em todas as instâncias (aulas ou tarefas) e suas práticas correspondem a atividades de reforço para a aprendizagem de línguas e para as 
pesquisas que devem apresentar (ensaios, relatórios, textos argumentativos, provas de conteúdo). Na entrevista 1, a estudante exemplifica essa percepção com a frase:

"es que todo se complementa al menos con la escritura, siempre. En las clases, por ejemplo, vemos alguna película, algún corto, algún comercial, y ahí hay que escribir sobre. Entonces sí, la escritura está muy presente en todo.

Uma apreciação importante sobre o processo de transição que a estudante percebe em sua formação acadêmica é a presente na entrevista 4, com a seguinte afirmação:

"el semestre pasado escribíamos más cosas literarias, pero ahora son cosas más académicas, menos libres. Ahora es solo trabajo y nada del otro. Lo que escribo es lo que me piden los profesores. Tuvimos hasta que aprender a hacer marcos teóricos y cosas así."

Parece haver nessas percepções acerca da escrita no contexto universitário um desconhecimento gerado pelas próprias práticas a que os estudantes se encontram expostos: a formação linguística e a formação disciplinar (CARLINO, 2004) encontramse desconectadas do potencial a que esta habilidade está destinada a desenvolver. Além disso, o contexto de formação dos estudantes de tradução está fundamentado na promoção do desenvolvimento de uma escrita "científica", portanto, a inclusão de novos gêneros em seus repertórios e a associação desses com o conteúdo das diferentes disciplinas é o que torna a sua experiência com essa habilidade mais complexa no âmbito acadêmico. Suas dificuldades em produzir esses novos gêneros, segundo os relatos exemplificados anteriormente, não se referem ao domínio linguístico, mas sim aos desafios impostos pelas exigências dos "novos" gêneros que devem produzir. A prática de escrita constante a que se referem as entrevistadas para consolidar os conteúdos trabalhados deveria estar conectada com as práticas de uso da língua na sua especialidade, tendo em vista que a produção de textos específicos que passaram a fazer parte da sua formação. Entretanto, nota-se que o espaço para a promoção de práticas complementares da escrita parece ainda não estar consolidado.

\section{Percepção 2: O potencial epistêmico da escrita}

As entrevistas revelam que os estudantes escrevem "de tudo". Seu contato com os gêneros que os professores pedem que escrevam se dá a partir da prática. Remarcam que ao início do curso não tinham ideia do que significava entregar um relatório ou um texto 
argumentativo para determinadas disciplinas. Na entrevista 2, a estudante conta que foi "muito difícil" conseguir passar nessas matérias com trabalhos escritos, pois ainda não sabiam como produzir esses textos. Outra percepção revelada na entrevista 3, representa a apreensão que tinham quando começaram a ter que produzir textos acadêmicos:

"era difícil al inicio. Lo que pasa es que, por lo menos yo, vengo de un colegio muy malo y en realidad acá en Chile los colegios no fomentan mucho la escritura".

Para esses estudantes, a escrita acadêmica consiste em um desafio, pois a forma como devem elaborar o conhecimento disciplinar não está acessível apenas por meio do contato com os gêneros textuais que lhes são solicitados, tal como discute Carlino (2004). Isso fica mais evidente no relato a seguir, em que o estudante revela como avalia e é avaliado pelos professores quando escreve. Ainda que ele não tenha muita certeza de como deve construir o gênero textual pedido por um determinado professor, sua estratégia é adaptar-se ao formato exigido:

"cada profesor corrige según sus propias pautas y generalmente cada profesor tiene su
propio estilo y en base a este estilo va a corregir cosas que uno escribe. Por ejemplo, hay
profesores que me corrigen ciertas cosas y otros que no". En cuanto a como yo lo escribo,
bueno, también he tenido que adaptarme a cada profesor en cuanto a sus requerimientos
y exigencias, pero por lo general no es tan difícil, bueno, ahora que ya estoy más
avanzado en la carrera, como que no es tan difícil apegarme a las exigencias de cada
profesor y de cada asignatura. En un principio podría ser un poco más porque no tenía
la habilidad que tengo para escribir como tengo ahora".

Essa é também a opinião revelada na entrevista 2:

"depende del formato del texto o depende también del profesor, porque como que ya
sé cómo le gustan los informes a este profesor, lo voy a hacer adecuándome a cada
formato que él pida. Lo hago fijándome según el formato que pida el profesor y según
el profesor que sea."

A entrevistada 2 aponta que, para as provas, era muito importante saber a matéria e saber escrever sobre a matéria. Por esse motivo, nos primeiros semestres, ainda com a facilidade de poder usar anotações e materiais de consulta, não era fácil conseguir fazer 
boas avaliações. Com essa percepção, a entrevistada ressalta a relevância do conhecimento linguístico e discursivo para construir seus textos no marco dos requerimentos da escrita acadêmica:

"Teníamos que saber de la materia, porque el profesor nos daba la posibilidad, tal como usted nos dio el semestre pasado, de consultar nuestros apuntes, de usar nuestros cuadernos, pero no era como solo ir mirando y va a estar todo bien. Uno tenía que saber del tema igual."

\section{Percepção 3: Preocupações com a escrita em espanhol}

As principais preocupações dos quatro estudantes entrevistados relacionam-se com o uso do vocabulário adequado aos requerimentos dos textos (uso formal), uso de uma ampla variedade de conectores, uso de menos hiperônimos e busca de precisão dos termos nos textos. Os fragmentos das entrevistas destacados a seguir exemplificam suas preocupações:

\footnotetext{
Entrevistada 2: "si no estoy segura de alguna estructura, trato de buscar otra."

Entrevistado 4: "me preocupo de que el texto sea coherente y demuestre mi dominio del tema."

Entrevistada 3: "usar el vocabulario más específico para escribir. En cuanto a redacción y esas cosas, no tengo preocupaciones porque como que ya lo domino."
}

As dificuldades relatadas pelos estudantes se referem a aspectos típicos da escritura acadêmica: o desenvolvimento linguístico (especializado, já que se trata do contexto acadêmico de formação); o domínio de gêneros textuais específicos e o domínio dos fatores de textualidade (CARLINO, 2004). Por esses relatos, novamente não é possível afirmar que haja algum grau de interconexão entre as práticas de escrita promovidas pelo contexto acadêmico, embora os estudantes percebam que há aspectos comuns nessa habilidade que tornam suas produções mais "coerentes", pertinentes ao tema e à forma - vocabulário e estruturas - específicas.

\section{Percepção 4: Preocupação com a escrita em português}


Neste ponto, os estudantes entrevistados se mostram muito preocupados com relação à forma da língua. Mencionam que tentam evitar, em suas produções, os falsos amigos, querem assegurar-se do significado adequado das palavras (sinônimos, hipônimos, hiperônimos e antônimos) e de usar as palavras corretas segundo o nível de formalidade exigido pelo texto. Por esse motivo, consultam muitas vezes os dicionários antes de escolher o termo que empregarão. O ponto de coincidência nas respostas se refere ao cuidado com a regência verbal e com a posição dos pronomes oblíquos nas frases. A prosódia da língua (o ritmo) também é outro entre os temas referidos, já que percebem que ao escutar a frase produzida durante a leitura em voz alta, podem identificar se há sentido e avaliar se é uma frase em português.

Nas respostas destacadas a seguir, alguns desses aspectos sobressaem:

Entrevista 4: "pienso en mi lengua materna lo que quiero decir y a veces no encuentro las palabras para decir lo que quiero en la LE, entonces tengo que recurrir más a diccionarios que cuando escribo en mi propia lengua".

Entrevista 4: "usar bien los recursos que tengo porque a veces no sé bien cómo usar algo, entonces prefiero no usarlo para no arriesgarme. Lo que más me preocupa es escribir lo más correcto posible".

Entrevista 3: "muchos diccionarios. Al igual que en mi lengua materna, hago un esquema porque si no me pierdo en los muchos temas que tengo que escribir, no me llevan a los objetivos que, no sé, de los objetivos que yo mismo planteo..."

Entrevista 3 : "trato de escribirlo y leerlo para ver el tema de la entonación, si está correcta."

São aspectos que coincidem com o desenvolvimento da escrita na LM e na LE dos estudantes de tradução. Escrever "da forma mais correta possível”, usar estratégias semelhantes da LM e manter a atenção nos aspectos discursivos e linguísticos (JÚDICE, 2013) representam pontos de confluência para observar como a escrita em duas línguas parece complementar-se em termos de processo e significado (MATTHIESSEN, 2009).

\section{Percepção 5: Biletramento espanhol-português}

Apesar de os estudantes não se referirem ao tema da escrita em português como uma prática muito diferente das práticas de produção de textos em sua LM de forma explícita, comparam os dois processos em termos de graus de preocupação: recorrem mais a dicionários e gramáticas para as consultas em e sobre a língua estrangeira. Perceberam que o uso das preposições e dos pronomes são marcas importantes que diferenciam os 
dois sistemas, já que elementos do português aparecem em suas produções quando não deveriam. A entrevistada 2 afirma que, para sua escrita em espanhol, sente-se "traumatizada" com as preposições em português. Por esse motivo, recorre a consultas para saber se erra em sua LM por causa do português que aprendeu:

"a veces no me acuerdo como era en mi lengua y empiezo a buscar cosas muy simple como para estar más segura de lo que estoy escribiendo en español".

A mesma entrevistada 2 aponta que sua orientação para a produção escrita são os textos que ela já produziu em outras instâncias, os quais podem contribuir tanto com os problemas que apresentam (ou apresentaram, segundo as avaliações dos professores que os leram) como pelos aspectos positivos dos mesmos. Nessa percepção, reconhece-se a referência ao processo de escrita como contínuo, ou, em outras palavras, a relação de complementariedade que os processos de biletramento apresentam (HORNBERGER, 2003; 2013).

A entrevistada 3 destaca que, ao escrever em português, deve seguir um caminho que a afaste do espanhol, porque se não o fizer, cometerá erros que ela já "sabe". Como aponta Júdice (2013:151), a proximidade entre português e espanhol permite que o aprendiz identifique as semelhanças entre os dois sistemas, ao mesmo tempo em que se depara com dificuldades nos planos sintáticos e na construção textual em si mesma:

Entrevista 3: "Hay más diferencia entre la escritura en portugués y la escritura en español. Porque al hacerlo como literal como sería en español uno cae en el error. Entonces en las diferencias es donde uno tiene que estar más atento para poder lograr comunicar de forma adecuada lo que pretende comunicar."

A entrevistada 1, preocupa-se por não ter "um nível de português muito alto", por isso confessa sentir-se mais confortável produzindo textos acadêmicos em inglês - língua com a qual ela tem maior contato. Por esse motivo, para suas produções de texto em português, ela se dedica a buscar o vocabulário específico, consultar dicionários e colegas. Em sua opinião, é dado um destaque para o fato de que ainda lhe faltam conhecimentos de língua portuguesa para realizar determinadas tarefas, por isso considera a produção de textos tão difícil. No entanto, seu relato também revela que a estrutura discursiva de suas produções se vê afetada por essa falta de conhecimentos da língua, já ela não pode se fixar no gênero requerido ao atribuir mais importância ao emprego preciso do vocabulário e da sintaxe para os textos acadêmicos: 
Entrevistada 1: “Apesar de que son próximas las lenguas el uso constante es lo que
hace que uno domine la lengua, entonces, al menos en mi caso había tenido un contacto
más largo con el inglés que con el portugués entonces, en comparación con el inglés voy
como dos años atrás entonces yo creo que al salir de la carrera recién me voy a sentir
cómoda con el portugués y no voy a tener que pensar tres veces en lo que voy a escribir
(...) Cuando escribo en portugués tengo que hacer más consultas, ir a más diccionarios
talvez consultar algún amigo que sea de allá o a algún compañero que sepa más”. (...)
La estructura de los textos... es que depende de lo que me estén pidiendo escribir, porque
por ejemplo, cuando teníamos que escribir textos literarios, poemas, cuentos, termina
siendo más el contenido que la forma. En cambio ahora que estamos viendo cosas más
específicas, como críticas y esas cosas, ahí como que tengo todavía muchas falencias,
porque no recuerdo bien lo que tengo que hacer, para estar concentrada en el
vocabulario. Se me olvida que tengo que tener este y este elemento para producir una
reseña crítica, por ejemplo."

As categorias identificadas para as análises dos dados revelaram algumas especificidades do contexto desta pesquisa. Os estudantes conseguem refletir sobre seus processos de escrita em duas línguas como um espaço de produção de sentido disciplinar, em que o domínio discursivo não pode ser integrado por separações próprias do curriculum universitário. Ao mesmo tempo, reconhecem que devem se esforçar para terem consciência sobre as formas dos dois sistemas, LM e LE, as quais devem ser separadas.

\section{DISCUSSÕES FINAIS}

Os dados analisados demonstram que as percepções do biletramento para os estudantes entrevistados respondem aos objetivos desta proposta de pesquisa. Em suas opiniões, revela-se que, no processo de formação de tradutores no par linguístico espanhol-português, a escrita é a base de seus estudos, tanto para a aquisição dos registros especializados, quanto para a promoção do conhecimento e para a compreensão/produção de textos de acordo com seu âmbito acadêmico. As preocupações referidas ao uso da LM e da LE são muito semelhantes, como se observa nas análises apresentadas. Sua atenção está dirigida ao uso do vocabulário, às estruturas específicas que se diferenciam nas duas línguas, como é o caso da regência verbal e nominal e do uso de pronomes. O uso do dicionário é recorrente como apoio no momento em que escrevem em LE, ao passo que não é tão comum quando produzem textos em sua LM. 
A respeito da convivência das duas línguas de sua formação, espanhol-português, os estudantes demonstram que suas aproximações à escrita nas duas línguas acontecem de forma paralela. Consideravam suas experiências prévias com a escrita escassas e pouco úteis para as produções acadêmicas que devem realizar em seu atual contexto universitário. A aprendizagem da "escrita acadêmica" em duas línguas revela, para eles, uma correlação não tanto entre os textos que produzem, mas sim em termos de interferências entre os sistemas de língua em questão. Nas entrevistas, os estudantes afirmam que suas produções tanto em LM quanto em LE, em geral, estão construídas seguindo uma mesma base: esquema, leituras prévias, buscas de vocabulário. Ademais, reconhecem que a aprendizagem de diferentes gêneros textuais e domínios de escrita nas duas línguas é útil para gerar e ampliar sua consciência sobre a produção de sentido por meio dos textos, conforme é relatado em uma das entrevistas sobre a leitura em voz alta como recurso para a autocorreção e a elaboração de esquemas prévios para precisar os objetivos no texto.

Os dados obtidos com as entrevistas permitem responder parcialmente à pergunta de pesquisa proposta, já que, com as análises realizadas ainda não é possível afirmar que os estudantes tiveram uma percepção explícita sobre a escrita como um processo contínuo nas diferentes línguas que aprendem. Porém, algumas de suas percepções são especialmente úteis para gerar novos instrumentos de verificação da mesma pergunta, como por exemplo: a) a facilidade que percebem sobre escrever no contexto universitário a partir de um acúmulo de experiências com os textos em diversas disciplinas; b) a coincidência dos gêneros textuais nas diferentes disciplinas, o que os leva a adaptar-se aos requerimentos das tarefas solicitadas pelos professores e c) a influência constante das línguas que conhecem em suas produções escritas. Algumas dessas preocupações parecem refletir a ideia de que o contexto universitário de formação de tradutores consiste num espaço potencial para o biletramento. Há uma implícita complementariedade da habilidade de escrever nas duas línguas, já que estão atentos a produzir textos “da forma mais correta possível", a usar estratégias de planejamento e pesquisa prévia antes de construir seus textos e a usar adequadamente os recursos discursivos e linguísticos em seus textos. Para Matthiessen (2009), esse conhecimento de repertórios de registro amplia a consciência acerca da produção de textos em termos de processo e significado.

Para a pesquisa apresentada neste artigo, os estudantes que participaram das entrevistas encontram-se no nível intermediário de desenvolvimento da língua 
portuguesa. Reconhecem que as diversas instâncias de práticas com a escrita moldam sua forma de percebê-la. Acerca da interação de conhecimentos entre os sistemas linguísticos que aprendem, suas percepções reforçam os aspectos morfossintáticos, ainda sem mencionar uma possível correlação de seu desenvolvimento de escrita nas línguas a que estão expostos. Esse fato poderia indicar que a compartimentação de conhecimentos nas muitas disciplinas (os saberes disciplinares aos quais necessitam aceder) e a visão de que "cada professor avalia de modo diferente os textos produzidos" não lhes permite ver a escrita como uma habilidade complexa, interconectada e dependente das experiências em sua formação acadêmica. Isso permite projetar outras formas de extensão deste trabalho, como por exemplo, a utilização, a título de comparação, da análise de textos escritos produzidos ao longo de determinado período e em diferentes disciplinas acadêmicas, com características de um estudo longitudinal, a fim de identificar se as influências referidas por esses estudantes são efetivamente verificáveis.

As práticas de produção de textos estão na base da formação acadêmica que esses futuros tradutores recebem e as duas línguas, espanhol e português, compartilham características de seus sistemas linguísticos, o que permite que os processos de compreensão e produção de textos sejam uma constante em seus estudos (ainda que as dificuldades no domínio morfossintático da LE esteja presente). O biletramento pode ter espaço no contexto analisado desde que os estudantes de tradução reconheçam os domínios específicos da escrita em uma e em outra língua, segundo os requisitos disciplinares específicos. Além disso, aspectos como o valor da escrita, as experiências prévias com o letramento, a motivação e as expectativas de usos das línguas devem ser avaliadas como variáveis para futuros trabalhos que indaguem a relação dos aprendizes hispano-falantes de português com a produção textual, em um contexto de formação universitária.

\section{REFERÊNCIAS}

ALMEIDA FILHO, J.C.P. Uma metodologia específica para o ensino de línguas próximas? Em: Almeida Filho, J. C. P. (Org.). Português para estrangeiros interface com o espanhol. Campinas, SP: Pontes, 1995. Pp. 13-21.

ALONSO REY, M.R. El mito de la facilidad en el estudio del proceso de enseñanza aprendizaje de PLE-HE. Estudios Portugueses 4, 2005. Pp. 11-38. 
BUITRAGO, S. H., RAMÍREZ, J. F. \& Ríos, J. F. Interferencia lingüística en el aprendizaje simultáneo de varias lenguas extranjeras. Revista Latinoamericana de Ciencias Sociales, Niñez y Juventud, v. 2, n.9, pp. 721 - 737, 201.

CARLINO, P. Escribir a través del curriculum: tres modelos para hacerlo en la universidad. In: Lectura y Vida. Revista Latinoamericana de Lectura, v. 25, n. 1, pp.1627, 2004.

Alfabetización académica diez años después. Revista Mexicana de Investigación Educativa, v.18, n.57, pp. 355-381, abr./jun. 2013.

CHO, S Academic biliteracy challenges: Korean scholars in the United States. Journal of Second Language Writing, v.19, n.2, pp. 82-94, 2010.

COLOMBI, M. C. Gramatical metaphor: academic language development in Latino students in Spanish. In: Byrnes, H. Advanced Language Learning: The contribution of Halliday and Vygotsky. Continuum: London, 2006. Pp. 147-162.

CORONADO, M.A. D. Porque escribir se aprende escribiendo. Una propuesta para el aula de ELE. Tejuelo, n. 24, pp. 92-110, 2016.

DA SILVA, A.M. O ensino de português como língua adicional: Especificidades e prática do contexto universitário inglês. Revista SIPLE, v.4. n.1, s.p., maio 2013.

DELL ISOLA, R. L.P. (Org.). Gêneros textuais: o que há por trás do espelho? Belo Horizonte: FALE/UFMG, 2012.

DUARTE, R.Entrevistas em pesquisas qualitativas. Educar, n. 24, pp.213-225, 2004.

FERREIRA, I.A. Português/espanhol - fronteiras linguísticas que devem ser delimitadas. In: ALMEIDA FILHO, J.C.P. (Org.). Português para estrangeiros: interface com o espanhol. Campinas, SP: Pontes, 1998. Pp. 34-48.

FERREIRA, M. M \& LOUSADA, E. G. Ações do Laboratório de Letramento Acadêmico da Universidade de São Paulo: promovendo a escrita acadêmica na graduação e na pósgraduação. Ilha do Desterro, v. 69, n.3, pp. 125-140, set/dez 2016.

FERNÁNDEZ-RODRÍGUEZ, M. Como aprender a aprender e melhorar a produção escrita em Português. In: JÚDICE, N \& PINTO, P.F. (orgs.). Para acabar de vez com Tordesilhas. Lisboa: Colibri, 1998. Pp.65-89.

GENTIL, G. Commitments to academic biliteracy. Case studies of francofone university writers. Written communication, v. 22, n. 4, pp. 421-471, 2005.

A biliteracy agenda for genre research. Journal of Second Language Writing, v.20, n.1, pp. 6-23, 2011.

GOMES, V.M.C \& PINHEIRO-MARIZ, J. Gêneros textuais na aprendizagem da escrita em francês língua estrangeira. Revista Prolíngua, v.6, n.1, jan./jun 2011. 
GRANNIER, D. M. Uma proposta heterodoxa para o ensino de portugués a falantes de español. Em: Júdice, N. (org.). Português para estrangeiros: perspectivas de quem ensina. Niterói: Intertexto, 2002. Pp.57-80.

GROSSO, M.J.R \& MOUTINHO, R. (2012). Mudança de atitude dos aprendentes chineses em relação à aprendizagem do português (PLE). Revista SIPLE, v.2, n.2, s.p.,outubro 2012.

HORNBERGER, N.H. (ED.). Continua of biliteracy: An ecological framework for educational policy, research, and practice in multi-lingual settings. Clevedon, UK: Multilingual Matters, 2003.

Biliteracy continua. In M. R. Hawkins (Ed.). Framing languages and literacies: Socially situated views and perspectives. New York, NY: Routledge, 2013. Pp. 149-167.

JIANG, $X$. The Role of first language literacy and second language proficiency in second language reading comprehension. The Reading Matrix, v. 11, n. 2, pp.177-190, abril 2011.

JÚDICE, N. Ensino de português para hispanofalantes: transparências e opacidades. In: JÚDICE, N. (org.). Português para estrangeiros: perspectivas de quem ensina. Niterói: Intertexto, 2002. Pp. 37-56

Módulos didáticos para grupos específicos de aprendizes estrangeiros de português do Brasil: uma perspectiva e uma proposta. In: GOTTHEIM, L. \& PEREIRA, A. L. (Orgs.) Materiais didáticos para o ensino de língua estrangeira - Processos de criação e contexto de uso. Campinas, SP: Ed. Mercado de Letras, 2013. Pp. 147-184.

KWON, H.J. \& SCHALLERT, D.L. Understanding translanguaging practices through a biliteracy continua framework: Adult biliterates reading academic texts in their two languages. The Journal of the National Association for Bilingual Education, v. 39, n.2, pp.138-151, 2016.

MARCUSCHI, L. A. Da fala para a escrita: atividades de retextualização. 10 ed. São Paulo: Cortez, 2010.

REYES, I. Biliteracy among children and youths. Reading Research Quarterly, v.47, n.3, pp. 307-327, 2012.

RYSHINA-PANKOVA, M. A meaning-based approach to the study of complexity in L2 writing: The case of grammatical metaphor. Journal of Second Language Writing, v.29, pp. 51-63, 2015.

ROTTAVA, L. A produção escrita de aprendizes de português como língua estrangeira adicional: a referenciação como recurso de processamento sociocognitivo. Horizontes de Linguística Aplicada, v.9, n.2, pp.127-143, 2010.

SANTOS, I. O ensino de português como segunda língua para falantes de espanhol: teoria e prática. In: CUNHA, M. J. \& SANTOS, P. (orgs.) Ensino e Pesquisa em Português para 
Estrangeiros - Programa de Ensino e Pesquisa em Português para Falantes de Outras Línguas (PEPPFOL). Brasília: Edunb, 1999.

SCHEPPPEGRELL, M. J. The linguistics features of advanced language use: the grammar of exposition. In: BYRNES, H. Advanced Language Learning: The contribution of Halliday and Vygotsky. Continuum: London, 2006. Pp. 134-146.

SOARES, M. Letramento: um tema em três gêneros. Belo Horizonte: Autêntica, 2009.

VAN DER WALT, C. Active biliteracy? Students taking decisions about using languages for academic purposes. In: HABERLAND, M., LØNSMANN, D. AND PREISLER, B. (eds.) Language Alternation, Language Choice and Language Encounter in International Education. (pp. 103 - 124). Heidelberg: Springer, 2013. Pp.103-1224.

VASILACHIS DE GIALDINO, I. (coord.) La investigación cualitativa. In: VASILACHIS DE GIALDINO, I. Estrategias de investigación cualitativa. Barcelona: Gedisa, 2012. Pp.23-64 